\title{
Assessment and correction of BCC_CSM's performance in capturing leading modes of summer precipitation over North Asia
}

\author{
Zhiqiang Gong, ${ }^{\mathrm{a}}\left[\mathrm{D}\right.$ Muhammad Mubashar Dogar, ${ }^{\mathrm{b}, \mathrm{c}}$ Shaobo Qiao, ${ }^{\mathrm{d}} \mathrm{Po} \mathrm{Hu}^{\mathrm{d}}$ and Guolin Feng ${ }^{\mathrm{a}, \mathrm{d} *}$ \\ ${ }^{a}$ Laboratory for Climate Studies, National Climate Research Center CMA, Beijing, China \\ ${ }^{\mathrm{b}}$ Earth Science and Engineering Department, King Abdullah University of Science and Technology, Thuwal, Saudi Arabia \\ ${ }^{\mathrm{c}}$ Global Change Impact Studies Centre (GCISC), Ministry of Climate Change, Islamabad, Pakistan \\ ${ }^{\mathrm{d}}$ College of Atmospheric Sciences, Lanzhou University, Lanzhou, China
}

\begin{abstract}
This article examines the ability of Beijing Climate Center Climate System Model (BCC_CSM) in demonstrating the prediction accuracy and the leading modes of the summer precipitation over North Asia (NA). A dynamic-statistic combined approach for improving the prediction accuracy and the prediction of the leading modes of the summer precipitation over NA is alse proposed. Our results show that the BCC_CSM can capture part of the spatial anomaly features of the first two leading modes of NA summer precipitation. Moreover, BCC_CSM regains relationships such that the first and second mode of the empirical orthogonal function (EOF1 and EOF2) of NA summer precipitation, respectively, corresponds to the development of the El Nimo and La Nina conditions in the tropical East Pacific. Nevertheless, BCC_CSM exhibits limited prediction skill over most part of NA and presents a deficiency in reproducing the EOF1's and EOF2's spatial pattern over central NA and EOF2's interannual variability ${ }_{2}$ h $_{2}$ can be attributed the reasons why the model is unable to capture the correct relationships among the basic climate elements over the central NA, lacks in its ability to reproduce a consistent zonal atmospheric pattern over NA, and has bias in predicting the relevant Sea Surface Temperature (SST) modes over the tropical Pacific and Indian Ocean regions. Based on the proposed dynamic-statistic combined correction approach, compared with the leading modes of BCC_CSM's original prediction, anomaly correlation coefficients of corrected EOF1/EOF2 with the tropical Indian Ocean SST are improved from 0.18/0.36 to 0.51/0.62. precipitation prediction over NA and its ability to capture the dominant modes could be certainly improved by choosing proper historical analogue information.
\end{abstract}

KEY WORDS leading modes; assessment; prediction; dynamic-statistic combined correction

Received 20 June 2017; Revised 21 August 2017; Accepted 30 September 2017

\section{Introduction}

North Asia (NA) located in the mid-high latitude region of the Northeast Hemisphere, which can roughly be divided into two distinct climatic regions. The southeastern parts influenced by the monsoon system have typical wet climate especially in summer, while the northwestern parts mainly controlled by the westerlies are one of the aridest zones around the world (Aizen et al., 2001; Huang et al., 2013). These features render NA as one of the unique regions among the same latitude, which deserves lots of attention from the meteorologists. A better and skilful seasonal precipitation prediction for NA, especially in the summer and winter season would be of great help to reduce the economic losses caused by natural disasters relevant to precipitation.

\footnotetext{
* Correspondence to: G. L. Feng, Laboratory for Climate Studies, National Climate Research Center CMA, Zhongguancun South Street No. 46, National Climate Center, Beijing 100081, China. E-mail: fenggl@cma.gov.cn
}

Previous studies have examined precipitation variations on interannual and decadal time scales in the NA based on different approaches (He et al., 2008; He et al., 2016). Huang et al. (2012) suggested that the summer precipitation decreased significantly over Northeast and North China, around the late-1990. This interdecadal summer precipitation change was accompanied by the weakening of the subtropical high-level westerly jet over East Asia (Kwon et al., 2007) and the low-level anticyclonic circulation anomalies (Ding et al., 2008; Zhou and Huang, 2010). In terms of the interannual variation, Huang et al. (2013) identified that the annual precipitation showed opposite variations between the westerlies-dominated arid Central Asia and monsoon-dominated North China during 1961-2009. Aizen et al. (2001) argued that the impacts of the western jet stream and the zonal atmospheric pattern played an important role in influencing precipitation in mid-high latitude Asia during the last century. It is also noted that the leading modes that may contain the dominant features of spatial anomalies and their interannual variation are more predictable (Zhou et al., 2009; 
Zhou et al., 2013). However, previous analysis was mainly focused on the accumulative summer precipitation rather than the leading modes.

The zonal teleconnection is an important factor affecting the summer precipitation over the NA. For example, the zonally originated teleconnection pattern along the Asian jet at the upper troposphere over the Eurasian continent (Lu et al., 2002) and the boreal summer stationary circumglobal teleconnection pattern over the Northern Hemisphere (Ding and Wang, 2005) might have caused zonal structure of East Asian summer precipitation. Chen and Huang (2012) further revealed that the precipitation variations in the Northwest China were affected by the Silk Road pattern and the Europe-China pattern. Meanwhile, the summer precipitation is also affected by the low latitude sea surface temperature pattern. For example, the El Nino Southern Oscillation (ENSO) is considered as one of the most important factors influencing the summer precipitation in South Asia (Dogar et al., 2017) as well as Northeast, and North China (NC) through the bridge of Indian monsoon-walker circulation (Ding and Wang, 2005). Lu (2004) and $\mathrm{Lu}$ (2005) revealed that the air-sea interaction in the eastern tropical Pacific Ocean influences the moisture transport to the NC and the summer rainfall variations through altering the location of the upper-level westerly jet stream. Gao et al. (2014) and Yang et al. (2007) suggested that an Indian Ocean Sea Surface Temperature Anomaly (SSTA) following ENSO can induce robust climate anomalies over the Indo-western Pacific region and also affects the mid-latitude atmospheric circulation and precipitation in summer. Recent studies also suggest that the tele-interactions between the mid-high latitude atmospheric circulation and the tropical SST should be considered in the prediction of the summer precipitation over NA.

Since 2005, Beijing Climate Center has been working on developing the climate system model (BCC_CSM) with the components such as atmosphere, land surface, ocean, and sea ice, which reflects a certain prediction ability of climate variability in the seasonal scale (Wu et al., 2013). Liu et al. (2015) accessed the performance of the seasonal prediction of the Asian Summer Monsoon by BCC_CSM. Significant skills are found in the model's prediction of certain aspects of South and Southeast Asian summer monsoon climatology and variations of Sea Surface Temperature (SST) anomalies over the tropical Pacific and Indian oceans. Nevertheless, deficiencies such as significant atmospheric errors over the tropical western North Pacific and the eastern equatorial Indian Ocean, incorrect translations from the SST into successful predictions of the Asian summer monsoon were also found. Gong et al. (2017) revealed that the BCC_CSM lacks in the ability to reproduce the meridional tripole pattern of summer precipitation over East Asia-West Pacific. This deficiency can be attributed to the BCC_CSM's failure to capture the summer East Asia-Pacific teleconnection and the BCC_CSM's limitation in generating correct atmospheric responses to SST forcing over the Indonesia maritime continent. It is also noted that the assessment of the performance of the seasonal prediction of the zonal pattern over mid-high latitude Asia by BCC_CSM has not been done yet. Accordingly, it is necessary to assess how well the BCC_CSM captures the leading modes of interannual variability of summer precipitation over NA. There have been assessments on the model prediction performance (Liu et al., 2015), however, few studies focus on developing new approaches for modifying the BCC_CSM's original output and improving the seasonal precipitation prediction skill in East Asia (EA) and NA. Therefore, a relevant study is quite necessary and will be of great help for achieving the objective of improving model's prediction accuracy.

Due to the reasons that atmospheric circulation has the nonlinear tele-responses to the external forcing and atmospheric motion exists the chaotic internal process, the dynamical model has limited ability in properly predicting seasonal climate anomalies in East Asia. This status in recent years has motivated researchers to consider how the seasonal prediction skill of the climate model can be effectively improved through the dynamic-statistic combined approach (Huang et al., 1993; Wang et al., 2012; Feng et al., 2013; Gong et al., 2016a). Based on this concept, plenty of statistic-dynamic combined prediction strategies have been developed and applied in operational applications (Lang and Wang, 2010; Fan et al., 2012; Liu and Fan, 2013). These studies suggest that the available observations and BCC_CSM hindcasts need to be used for exploring the historical analogue information and modifying model's deficiency in the prediction of the seasonal precipitation.

Based on the statement above, the BCC_CSM's performance of summer precipitation prediction accuracy and capturing leading zonal modes of summer precipitation over NA are assessed in Section 4. Responses of atmospheric circulation to SST anomalies both in reanalysis observation and model are analysed in Section 5. In Section 6, an approach by merging the tropical SST corresponded analogue information and model output is proposed for correcting BCC_CSM's leading modes of summer precipitation over NA. Finally, a brief conclusion is given in Section 7.

\section{Model and data}

The BCC_CSM used in this study is a global ocean-land-ice-atmosphere-coupled climate system model developed by Beijing Climate Center of China. It is composed of a T106 horizontal resolution and 26 hybrid sigma/pressure layers in the vertical direction, produces a seasonal forecast for 24 as the ensemble forecast by a lagged average forecasting with a combination of different atmospheric and oceanic initial conditions at the end of the month (Wu et al., 2013). The hindcasts are initiated from the first day of each March from 1991 to 2015 and ended with a 13-month integration. Based on a nudging method, the four-times daily air temperature, winds, and surface pressure fields of the National Centres for Environmental Prediction (NCEP) reanalysis are used as the atmospheric initial conditions, and the sea surface temperature of 
the NCEP Global Oceanic Data Assimilation System is used for the oceanic initial conditions. In this article, 24-member ensemble mean of predicting elements in terms of surface precipitation, geopotential height, zonal, and meridional wind, vertical velocity at multilevel, and sea surface temperature are generated by the BCC_CSM. The annual summer (June, July, August, JJA) average over the NA region $\left(30^{\circ} \sim 65^{\circ} \mathrm{N}, 60^{\circ} \sim 160^{\circ} \mathrm{E}\right)$, with an interpolated horizontal resolution of $2.5^{\circ} \times 2.5^{\circ}$ are applied for the model output.

The reanalysis data used for the verification of model results includes multilevel zonal wind, meridional wind, geopotential height, and vertical velocity are from the NCEP reanalysis data sets (Masao et al., 2002). The CPC (Climate Prediction Center, National Weather Service, US) merged analysis of precipitation (CMAP) monthly data from 1991 to 2015 are taken as precipitation reanalysis observation (Xie and Arkin, 1997). The model errors, namely the difference between the model and the CMAP data, are obtained (Xiong et al., 2011). The extended reconstructed monthly SST from 1991 to 2015 produced by the National Oceanic and Atmospheric Administration (NOAA) is taken as SST reanalysis observation (Smith et al., 2008). A Student's $t$-test is used for the correlation significance analysis, and the $F$-test is used for the regression significance analysis in this study.

\section{Leading zonal modes of summer precipitation in NA}

Spatial distribution of anomaly correlation coefficient (ACC) of summer precipitation between the reanalysis and BCC_CSM predictions during 1991-2015 exhibited limited prediction skill over parts of Southeast and Northeast NA (Figure 1). In order to reveal the reason for the low prediction accuracy of the summer precipitation, the observed two leading zonal modes of the summer precipitation in NA are presented in Figure 2 by applying the The empirical orthogonal function (EOF) analysis to the anomalies of summer precipitation reanalysis. The notable feature of The first empirical orthogonal function mode (EOF1) (Figure 2(a)) is the north dry-south wet pattern, major positive anomalies located at the northwest of Baikal Lake, and the Sea of Okhotsk, while a rainy belt dominates the region between $30^{\circ}$ and $50^{\circ} \mathrm{N}$ from west to east. The observed spatial pattern The second empirical orthogonal function mode (EOF2) (Figure 2(b)) shows a northwest-southeast wave structure, with two positive lobes, respectively, distributed to the west of Baikal Lake, Japan, and offshore area, and with two negative lobes, respectively, located in North China and Far East Russia. EOF2 also presents the north wet-south dry pattern in the eastern NA. The EOF1 of BCC_CSM (Figure 2(c)) presents the zonal wave pattern with two negative lobes, respectively, distributed in Kazakhstan, Japan, and the eastern offshore, and with one positive anomaly centre located in North China. The meridional dipole patterns in western and eastern NA are also observed in BCC_CSM's

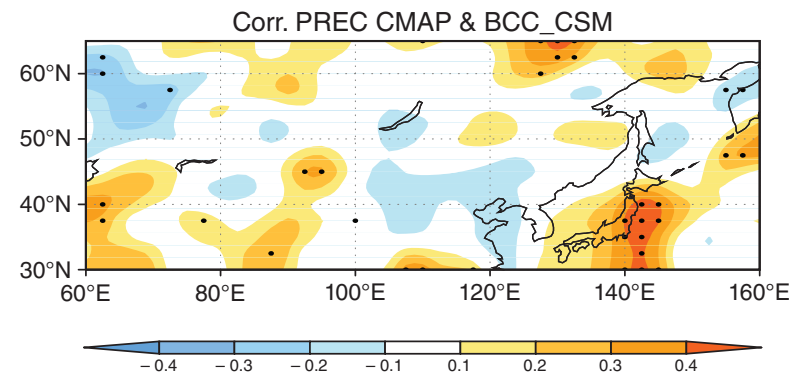

Figure 1. Spatial distribution of ACCs of the summer precipitation between the reanalysis and BCC_CSM during 1991-2015. Dotted areas indicate the $95 \%$ significance level. [Colour figure can be viewed at wileyonlinelibrary.com].

EOF1. The spatial ACC of EOF1 between reanalysis and BCC_CSM is 0.18 , passing the $95 \%$ significance level. It is also noted that the anomalies over central NA of BCC_CSM is out of phase with reanalysis. BCC_CSM's EOF2 mode (Figure 2(d)) shows the similar tripole pattern in the western NA and dipole pattern in the eastern part as reanalysis, but exhibits a different structure over the central NA. The ACC of EOF2 between reanalysis and BCC_CSM is 0.36 , passing the $95 \%$ significance level, while the anomalies of reanalysis over the central and southwestern NA are out of phase.

The principal components (PCs) of the first two leading modes of summer precipitation anomalies are presented in Figure 3. The PC1 of reanalysis and BCC_CSM both show the interannual and interdecadal variations (Figure 3(a)), with a correlation as 0.40 , passing the $95 \%$ significance level. These two distinct temporal scale variations are also found in the PC2 (Figure 3(b)), while the correlation of PC2s is only 0.06 , lower than the $95 \%$ significance level, which implies that the model is not able to correctly predict the EOF2's interannual variability. The percentage of variance explained by the first 10 leading eigenvalues are shown in Figure 4, indicating EOF1's eigenvalue of BCC_CSM is much higher than the reanalysis while eigenvalues of EOF2-EOF10 are close to or lower. Accordingly, BCC_CSM can reproduce part of the spatial anomaly characteristics of the first two leading modes of summer precipitation over NA, however, it shows the deficiency in reproducing the EOF1's and EOF2's spatial anomies over central NA and PC2's interannual variability, which may lead to the low prediction accuracy for summer precipitation over NA. According to recent studies (Chen and Zhou, 2014; Gong et al., 2016b), BCC_CSM's deficiency in the precipitation prediction could be attributed to its imperfect internal viability or atmospheric responses to the external forcing during the model predicting process.

\section{Atmospheric circulation associated with leading modes of summer precipitation}

Atmospheric circulation plays a crucial role in directly affecting the zonal precipitation in the subtropical region. For example, Zhou and Huang (2010) suggested that the 
(a) PREC_EOF1 CMAP

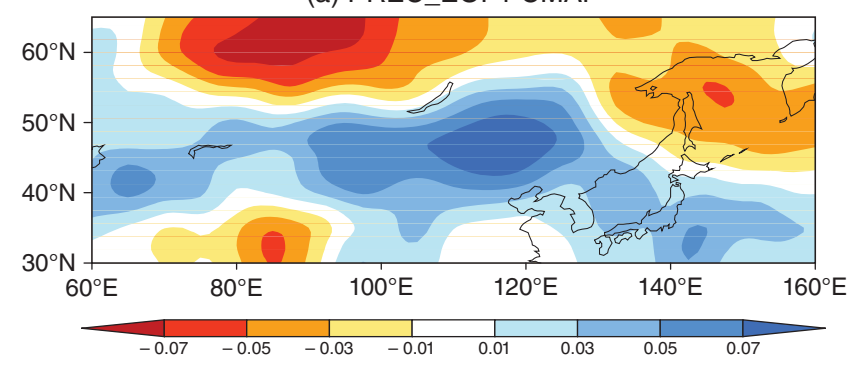

(c) PREC_EOF1 BCC_CSM

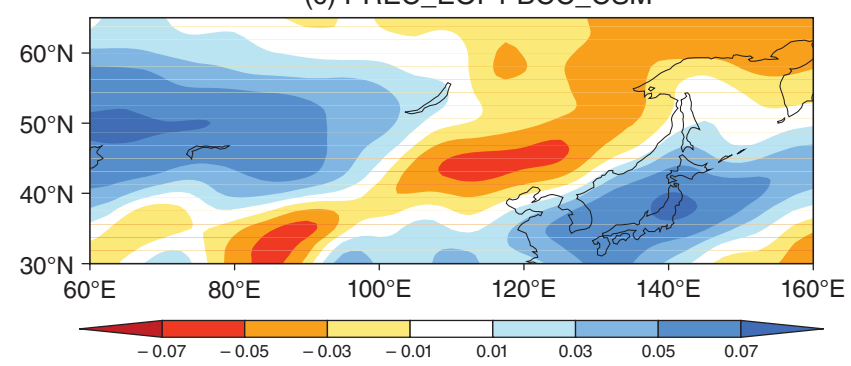

(b) PREC_EOF2 CMAP

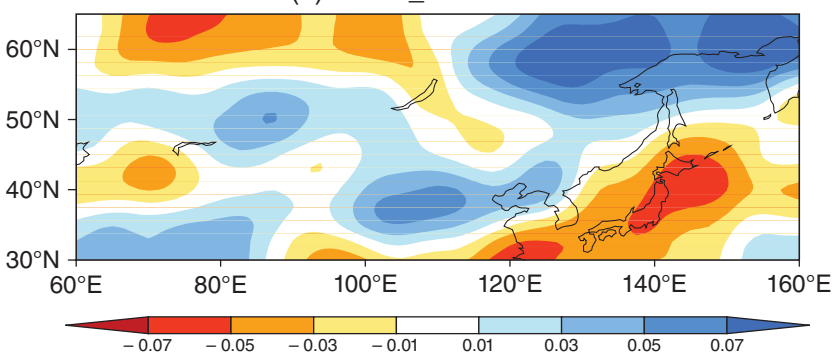

(d) PREC_EOF2 BCC_CSM

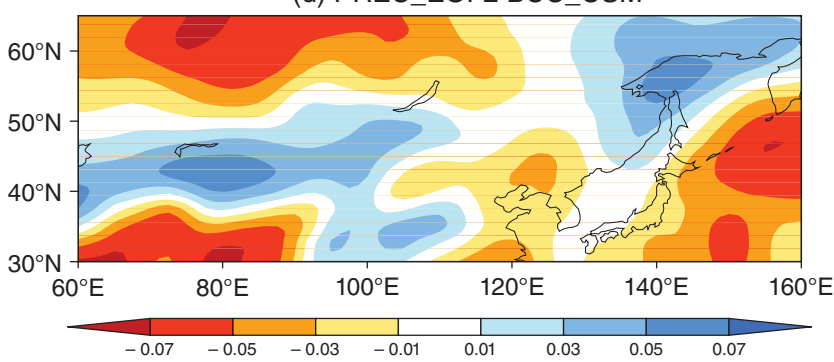

Figure 2. Spatial pattern of the EOF1 and EOF2 for summer precipitation anomalies over the region NA $\left(30^{\circ}-65^{\circ} \mathrm{N}, 60^{\circ}-160^{\circ} \mathrm{E}\right)$ during $1991-2015$ for $(\mathrm{a}, \mathrm{b})$ CMAP and (c, d) BCC_CSM. Variance percentage of reanalysis is $14.4 \%$ for EOF1 and $12.5 \%$ for EOF2, while it is $20.8 \%$ and $12.3 \%$ for BCC_CSM, respectively. [Colour figure can be viewed at wileyonlinelibrary.com].
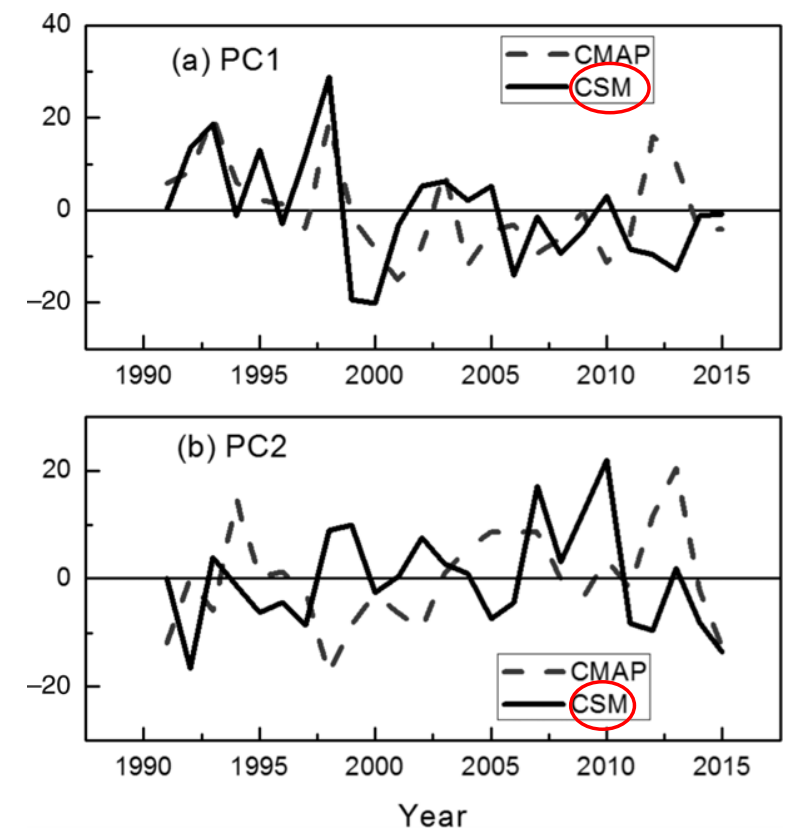

Figure 3. PCs of (a) EOF1 and (b) EOF2 of summer precipitation anomalies.

correlation of the summer precipitation between Northwest China and lower reaches of Yangtze River might be caused by the Silk Road pattern. Chen and Huang (2012) discussed that the wave-like pattern from North Atlantic to China as the Europe-China teleconnection could effecaffect the northwest-southeastward anomalies of summer precipitation. In this section, we will identify the association of summer precipitation over NA with other atmospheric elements in reanalysis and BCC_CSM, respectively.

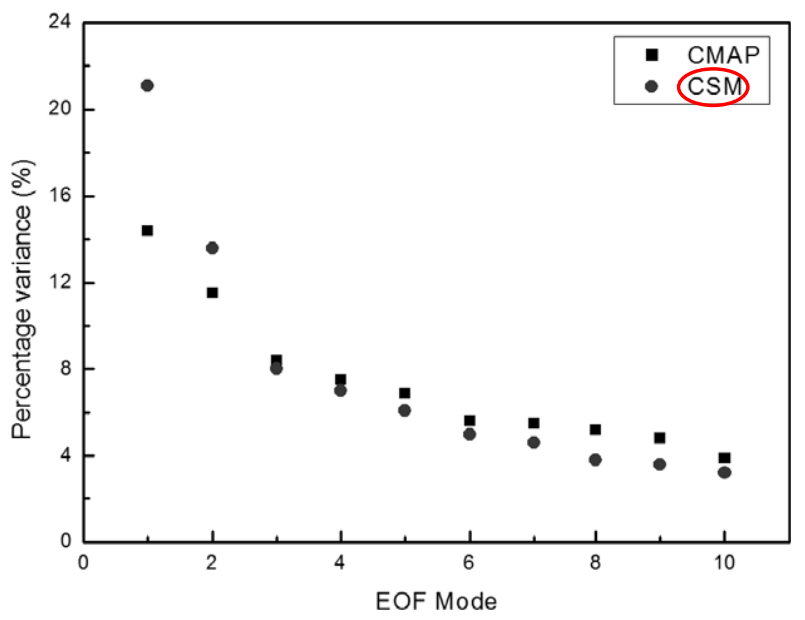

Figure 4. Percentage variance (unit: \%) explained by EOF1 - EOF10 of summer precipitation anomalies.

Figure 5 shows that the spatial pattern of the regressed vertical velocity anomalies at $500-\mathrm{hPa}$ onto $\mathrm{PC} 1$ of summer precipitation anomalies (Figure 5(a)) is consistent with the EOF1 of summer precipitation (Figure 2(a)). Upward motion anomalies mainly distributed at the regions $40^{\circ}-50^{\circ} \mathrm{N}$ of the Euro-Asia mainland, as well as Southern Japan and offshore areas. Anomalous downward movement mainly located at regions northwest of Baikal Lake, south of Balkhash Lake, and the Sea of Okhotsk. In Figure 5(c)), the spatial pattern of vertical velocity anomalies is consistent with the EOF1 pattern (Figure 2(c)) in the BCC_CSM. The regression of vertical velocity anomalies in BCC_CSM reproduces the similar pattern of vertical motion anomalies as the reanalysis in western and eastern NA, while it fails to 
(a) Reg. Oemga500 \& PC1 NCEP

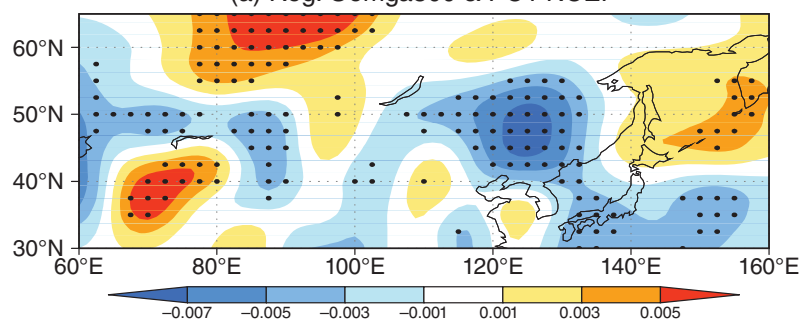

(c) Reg. Oemga500 \& PC1 BCC_CSM

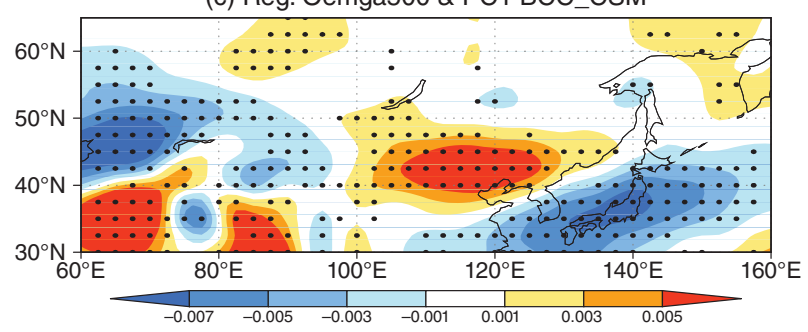

(b) Reg. Oemga500 \& PC2 NCEP

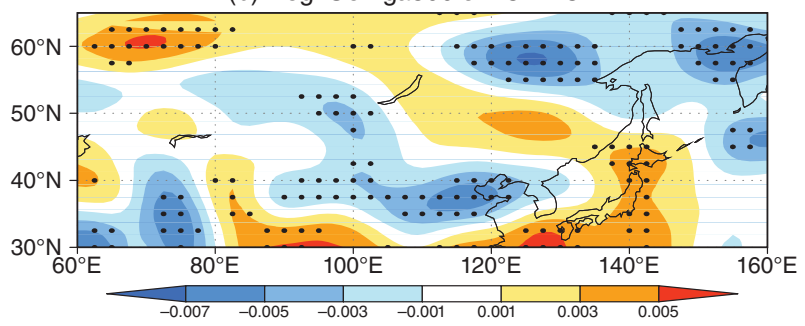

(d) Reg. Oemga500 \& PC2 BCC_CSM

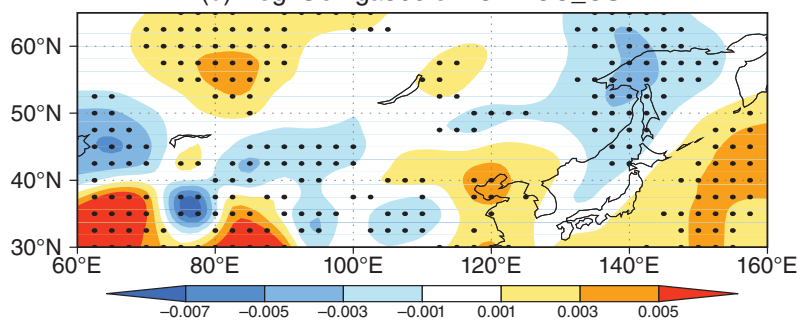

Figure 5. Regressions of vertical velocity anomalies at 500-hPa (omega, units: $\mathrm{Pa} \mathrm{s}^{-1}$ ) onto PC1 (a, c) and PC2 (b, d) of summer precipitation anomalies. (a, b) Reanalysis and (c, d) BCC_CSM. Dotted shadings indicate the 95\% confidence level. [Colour figure can be viewed at wileyonlinelibrary.com]

regain the distributions of vertical velocity anomalies over central NA. Corresponding to the observed EOF2 pattern of summer precipitation anomalies (Figure 2(b)), Figure 5(b) depicted the associated spatial structure of vertical velocity anomalies in reanalysis. Although the PC2 regressed vertical velocity anomalies exhibit a closely consistent spatial distribution as the summer precipitation in the BCC_CSM (Figure 2(d)), however, anomalous features are not well reproduced over the middle NA in the BCC_CSM (Figure 5(d)).

Corresponding to the EOF1 of summer precipitation anomalies (Figure 2(a)), the regressed geopotential height anomalies at $200-\mathrm{hPa}$ exhibit a zonal wave pattern in Figure 6(a) propagated by the wave activity flux from west to east. This zonal structure is associated with wave-train pattern along the polar-front jet over northern Eurasia caused by Rossby waves across the Eurasian continent (Iwao and Takahashi, 2008). The meridional tripole pattern is also observed in eastern NA with two positive lobes distributed in low and high latitude regions and one negative lobe at the subtropical region (Figure 6(a)). This meridional tripole structure is associated with the East Asia Pacific/Pacific Japan (EAP/PJ) teleconnection pattern revealed by Huang (1987) and Nitta (1987). The middle and northern part of the tripole pattern is corresponding to the dipole structure of summer precipitation observed in Eastern NA (Figure 2(a)). The PC2-regressed geopotential height anomalies (Figure 6(b)) show a significant wave pattern originated from the northeastern Europe and then propagate to southeast along the wave fluxes, which is well consistent with the EOF2 of summer precipitation anomalies presented in Figure 2(b). Chen and Huang (2012) revealed the Europe-China teleconnection indicating a northwest-southeast wave-like distribution from eastern Europe to southeast China, and resulting in the similar precipitation anomaly pattern presented in Figure 2(b). Unexpectedly, regressions of geopotential anomalies at 200-hPa onto the PC1 (Figure 6(c)) and the PC2 (Figure 6(d)) in BCC_CSM both demonstrate the zonal belt anomalies. They are obviously different from the reanalysis and do not match with the anomaly patterns of summer precipitation in Figures 2(c) and (d). It is also indicated that the wave fluxes of reanalysis over NA cannot be reproduced by the BCC_CSM.

At $700-\mathrm{hPa}$, the zonal wave train across the Eurasian continent (Figure 7(a)) and the northwest-southeast wave pattern from eastern Europe to Japan (Figure 7(b)) are, respectively, consistent with the wave structure in Figures 6(a) and (b), reflecting the wave trains along the northern Eurasia are known as Quasi-stationary Rossby wave in summer and recognized as equivalent Barotropic waves propagating along the waveguide (Lu, 2004; Kosaka et al., 2009). Overlapped with the anomalies of geopotential height, wind cyclones, and anticyclones coupled with each other from west to east in Figure 7(a) and from northwest to southeast in Figure 7(b). These two wave patterns can effectively influence summertime climate in Siberia, North China, and Japan (Chen and Huang, 2012; Chen et al., 2013) and then cause the summer precipitation modes of EOF1 (Figure 2(a)) and EOF2 (Figure 2(b)) in reanalysis, respectively. Nevertheless, geopotential anomalies regression at $700-\mathrm{hPa}$ onto $\mathrm{PC} 1$ (Figure 7(c)) and PC2 (Figure 7(d)) in BCC_CSM both demonstrate the zonal belt anomalies as those shown at the level 200-hPa, which are also obviously different from reanalysis observations. That is to say, the observed west-east wave pattern across the Eurasian continent and the northwest-southeast wave pattern in the geopotential height field are unable to be reproduced in BCC_CSM. Wind velocity anomalies at $700-\mathrm{hPa}$ presented in Figure 7 show the similar results as the geopotential height. 
(a) Reg PC1 \& Z200 Flux W NCEP

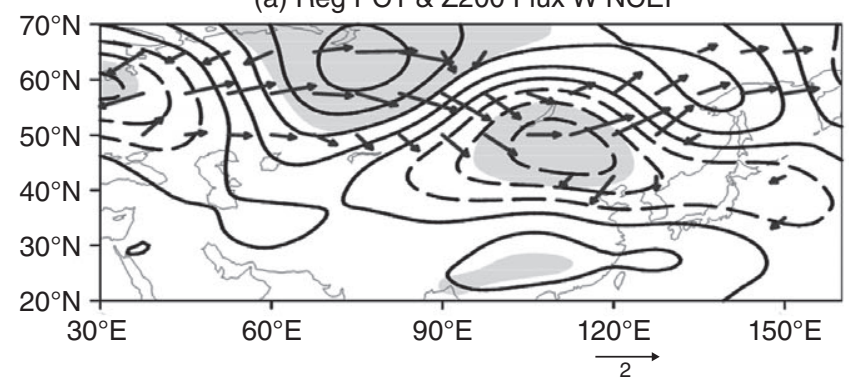

(c) Reg PC1 \& Z200 Flux W CSM

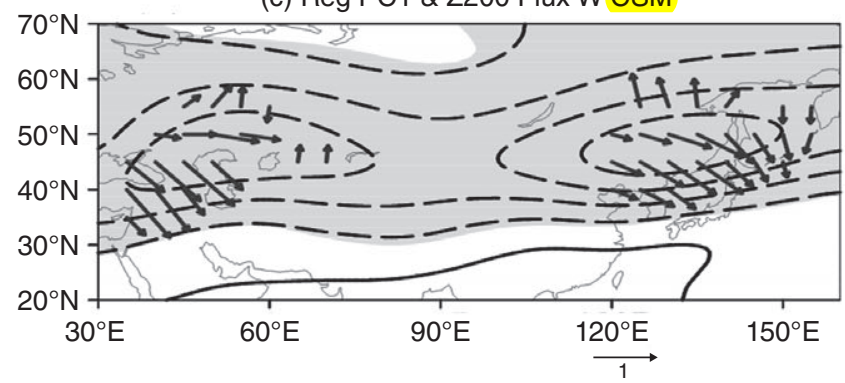

(b) Reg PC2 \& Z200 Flux W NCEP

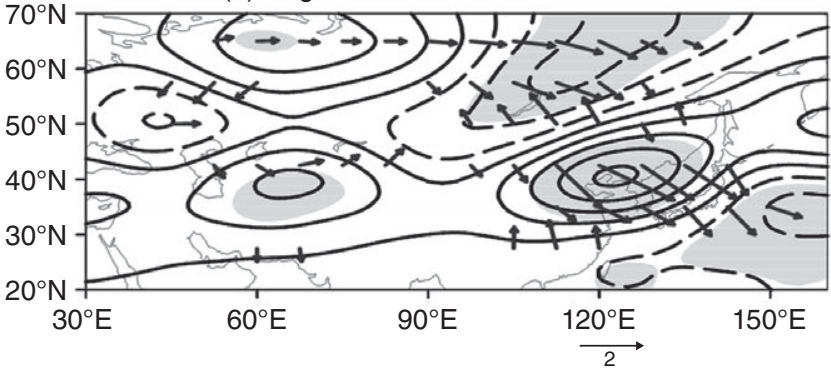

(d) Reg PC2 \& Z200 Flux W CSM

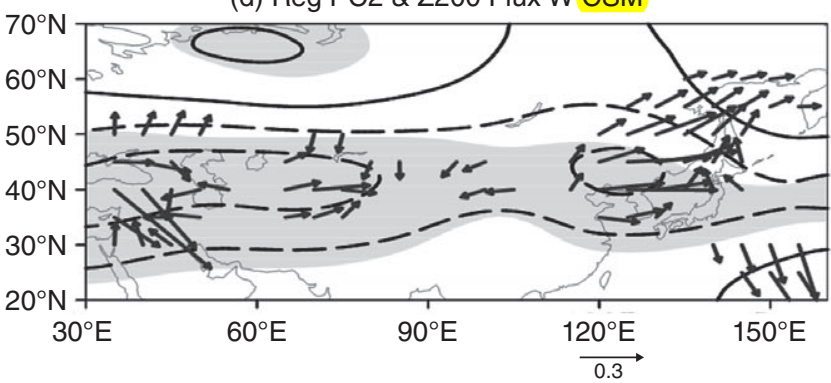

Figure 6. Same as Figure 5 but for the geopotential height (contours, units: gpm) and wave activity fluxes (vectors, units: $\mathrm{m}^{-2} \mathrm{~s}^{-2}$ ) at $200-\mathrm{hPa}$. Shadings indicate the $95 \%$ confidence level of the geopotential height.

(a) Reg. PC1 \& UVZ700 NCEP

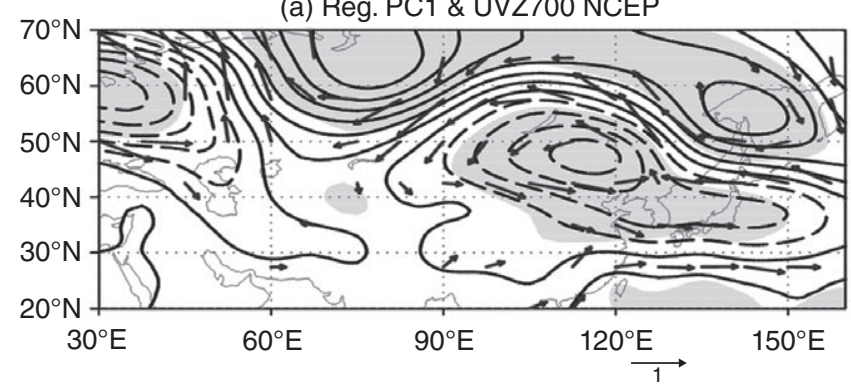

(c) Reg. PC1 \& UVZ700 CSM

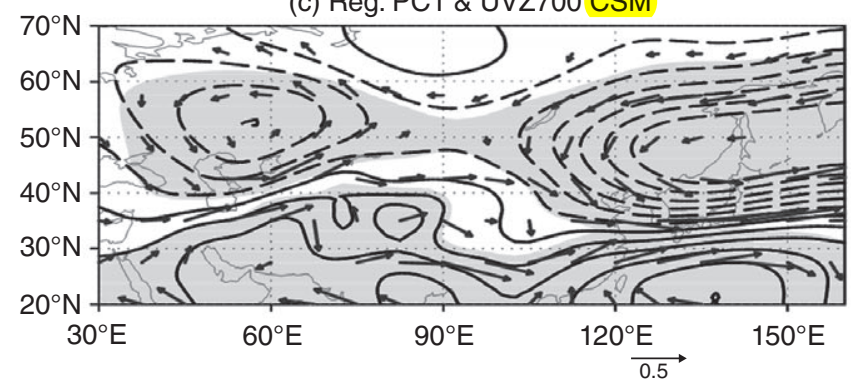

(b) Reg. PC2 \& UVZ700 NCEP

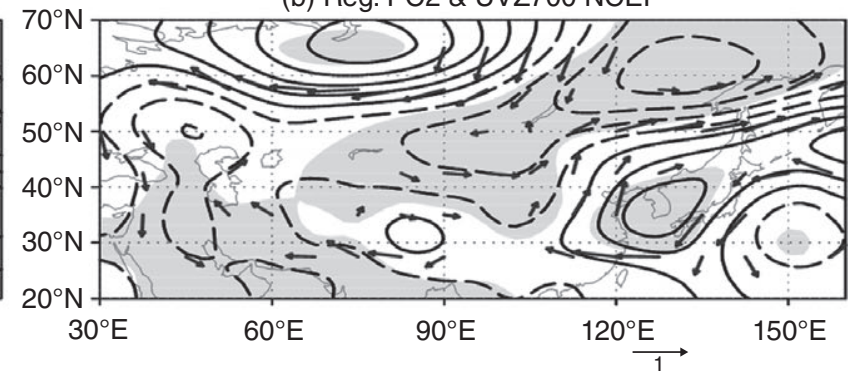

(d) Reg. PC2 \& UVZ700 CSM

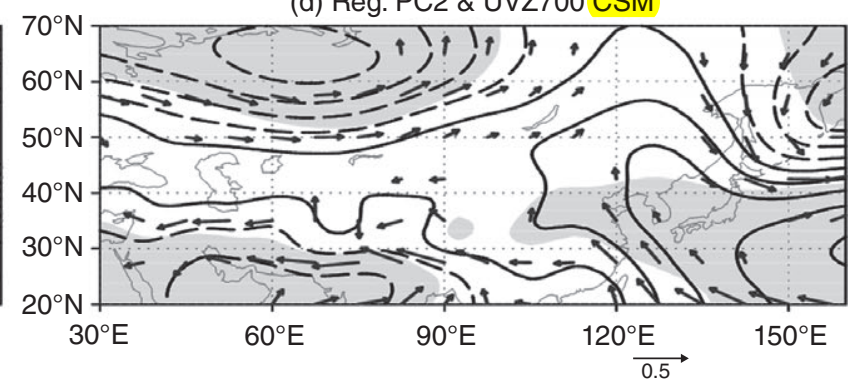

Figure 7. Regressions of geopotential height (contours, units: gpm) and wind (vectors, units: $\mathrm{ms}^{-1}$ ) at 700-hPa onto PC1 (a, c) and PC2 (b, d) of summer precipitation anomalies for (a, b) NCEP and (c, d) BCC_CSM. Shadings indicate the 95\% confidence level of the geopotential height.

To explain why BCC_CSM is lack of the ability to reproduce the leading modes of the summer precipitation anomalies, correlations among precipitation, geopotential height, and vertical velocity are analysed. The vertical velocity shows significant correlations with precipitation over most areas of NA except for Tibet region both in the reanalysis (Figure 8(a)) and the BCC_CSM (Figure 8(b)), reflecting that the model is able to reproduce the precipitation properly if the vertical velocity prediction is well predicted. However, the spatial distribution of correlations between geopotential height at $700-\mathrm{hPa}$ and vertical velocity at 500-hPa exhibit positive values over NA and surrounding regions in reanalysis but negative correlations in BCC_CSM (Figures 8(c) and (d)). The corresponding difference also exists in the correlations between the summer precipitation and the geopotential height at $700-\mathrm{hPa}$ (Figures 8(e) and (f)). Accordingly, the BCC_CSM is able to properly reproduce relationships among the summer precipitation, geopotential height anomalies, and vertical velocity in the western and eastern NA; however, it has 
(a) Corr. Prec \& Omega500 Obs.

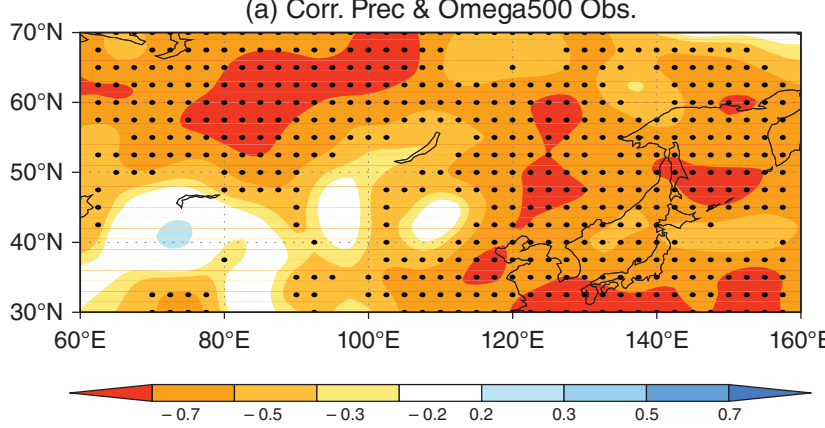

(c) Corr. Prec \& Z700 Obs.

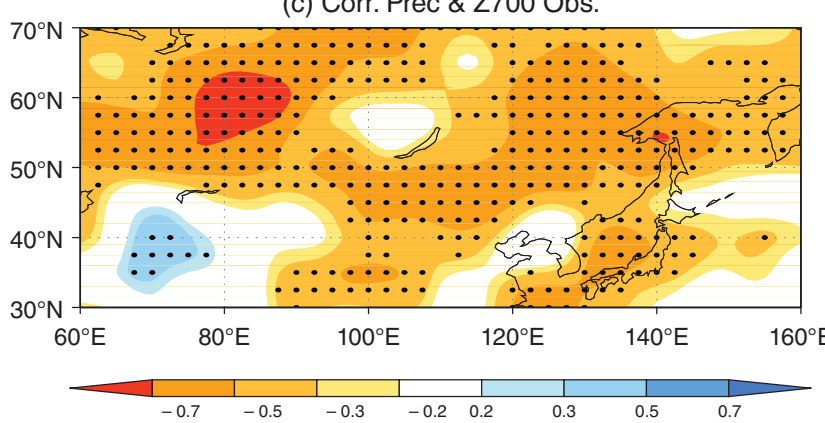

(e) Corr. Z700 \& Omega500 Obs.

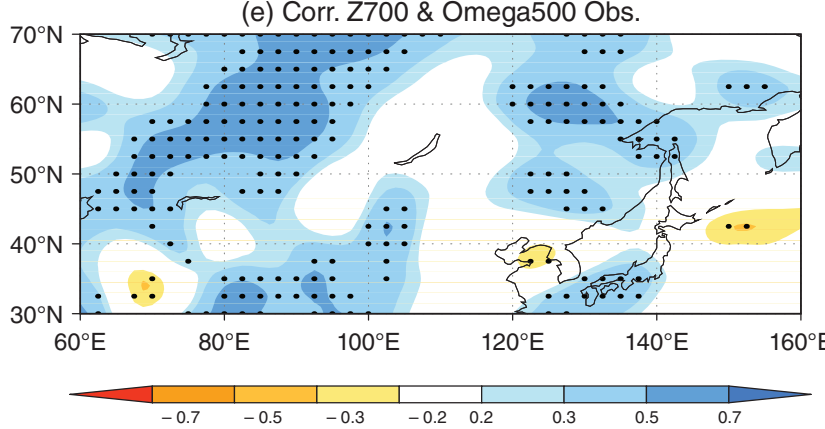

(b) Corr. Prec \& Omega500 CSM

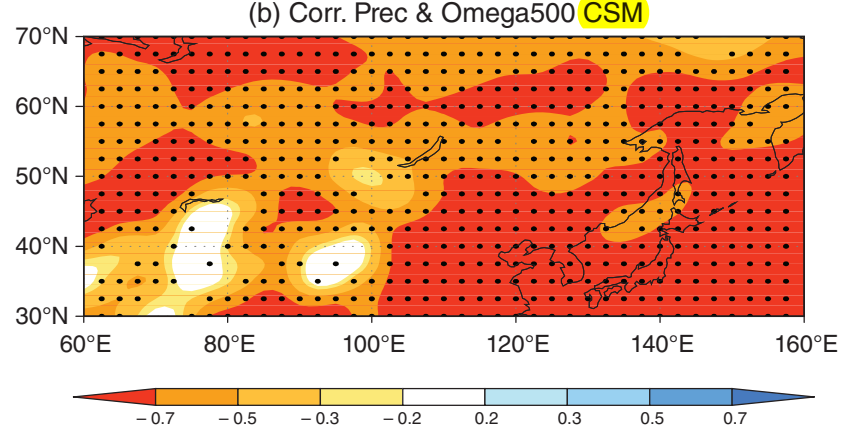

(d) Corr. Prec \& Z700 CSM
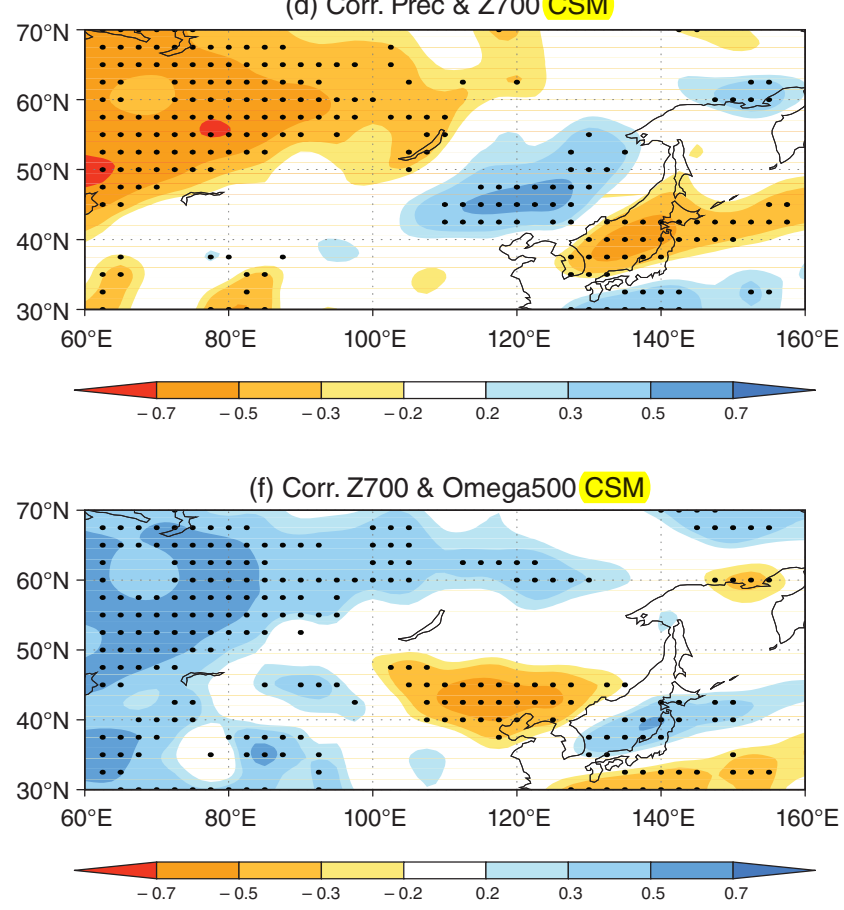

Figure 8. Spatial distribution of correlation coefficients between anomalies of precipitation \& Omega at 500-hPa (a, b), precipitation \& Z700 (c, d), and Z700 \& Omega at 500-hPa (e, f) in summer. Using NCEP (a, c, e) and BCC_CSM (b, d, f). Dotted areas indicate the 95\% confidence level. [Colour figure can be viewed at wileyonlinelibrary.com].

limitation in predicting correct geopotential height over the central NA. This limitation might be the direct reason for BCC_EAM,s failure to reproduce spatial modes and wave pattern in the geopotential height field, leading to the model's shortcoming in reproducing an accurate zonal pattern of summer precipitation over NA. It also explains, from the angle of atmospheric process, why BCC_CSM fails to reproduce the EOF1's spatial pattern and EOF2's interannual variability.

\section{Tele-responses of atmospheric circulation to SST anomalies}

Wang et al. (2008) have revealed that the remote forcing of SST over tropical East Pacific is one of the fundamental factors affecting the leading modes of atmospheric circulation over East Asia monsoon. Zhou et al. (2009) revealed that the multi-model ensemble (MME) could successfully capture the dominance of remote El Nino forcing in producing the predictable portion of
Australia-Asia Monsoon rainfall variability; however, it has the limitation in reproducing the local air-sea coupling effects, lending to the MME's deficiency in capturing the seasonal phase. Given these studies into consideration, regressions of preceding spring (March, April, and May; MAM) and summer (JJA) SST anomalies onto the PCs of summer precipitation anomalies are presented in Figure 9. The PC1-regressed seasonal SST evolutions from preceding MAM to JJA (Figures 9(a) and (b)), reflects a typical decaying process of El Nino condition over tropical East Pacific both in the reanalysis and the BCC_CSM. It is suggested that the success of BCC_CSM in capturing part of the general features of the first leading mode of summer precipitation over NA can be attributed to the model's ability to adequately reproduce the dominant mode of the tropical Pacific SST, especially the decaying El Nino conditions from preceding spring to summer. It is also noted that regressions over tropical Indian Ocean present weak anomalies in reanalysis while significant positive anomalies in BCC_CSM, suggesting that the responses of the 
(a) Reg. PC1\&SST Obs.MAM

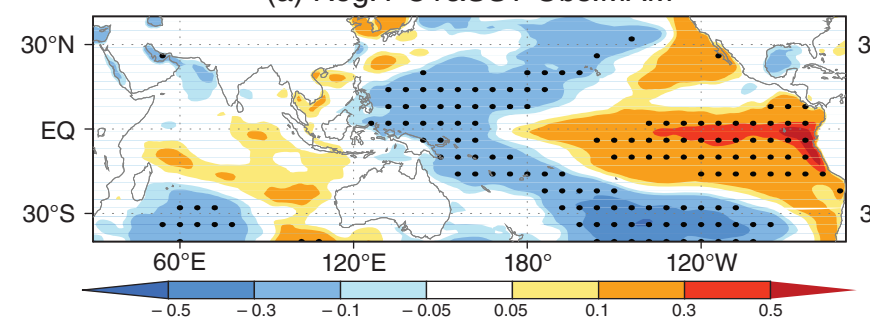

(c) Reg. PC1\&SST BCC_CSM MAM

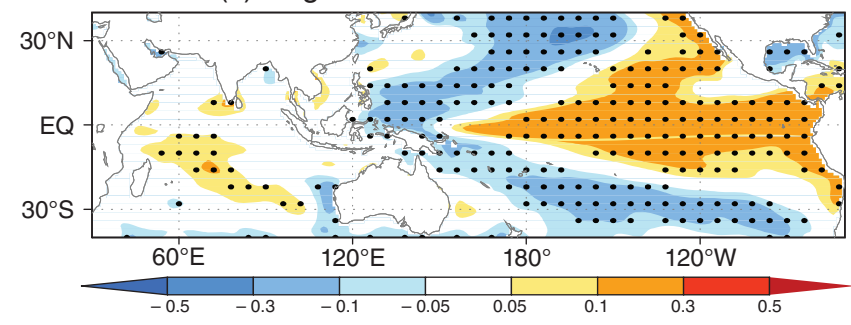

(b) Reg. PC1\&SST Obs.JJA

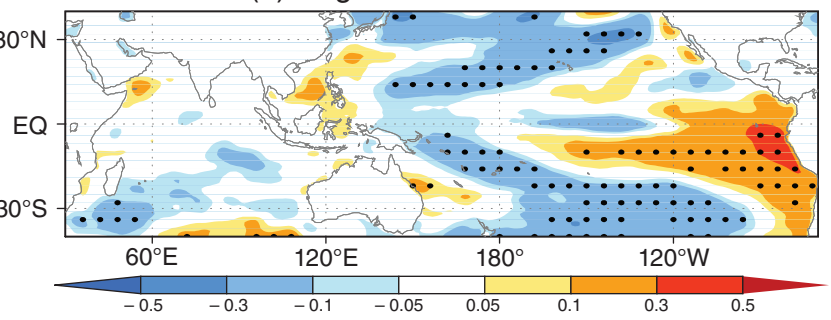

(d) Reg. PC1\&SST BCC_CSM JJA

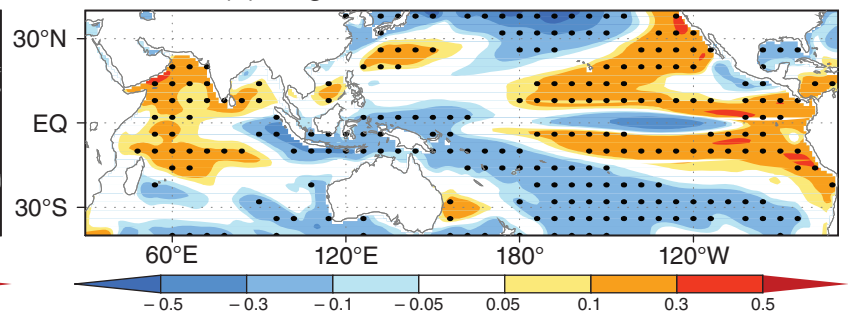

Figure 9. Regressions of spring (a, c) and summer (b, d) SST anomalies onto the PC1 of summer precipitation anomalies for (a, b) reanalysis and (c, d) BCC_CSM. The dotted areas indicate the 95\% confidence level. [Colour figure can be viewed at wileyonlinelibrary.com].

(a) Reg. PC2\&SST Obs.MAM

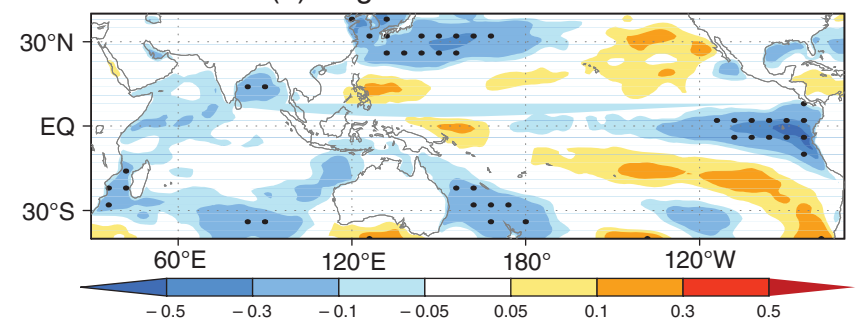

(c) Reg. PC2\&SST BCC_CSM MAM

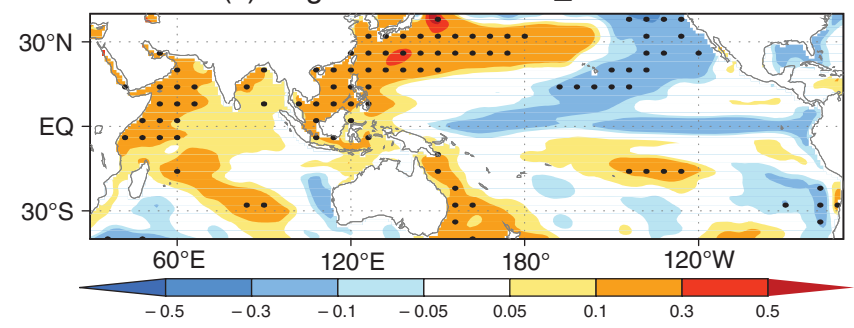

(b) Reg. PC1\&SST Obs.JJA

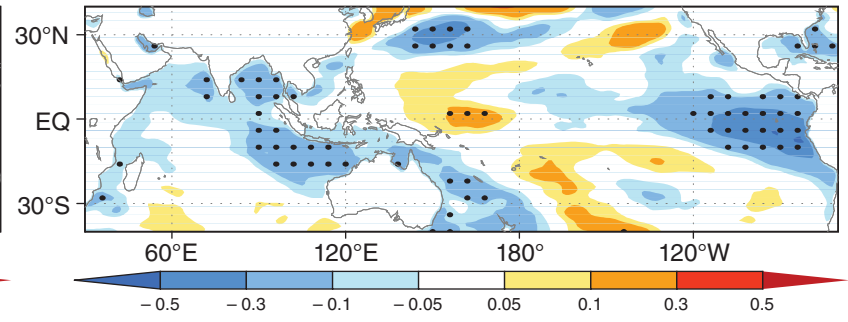

(d) Reg. PC2\&SST BCC_CSM JJA

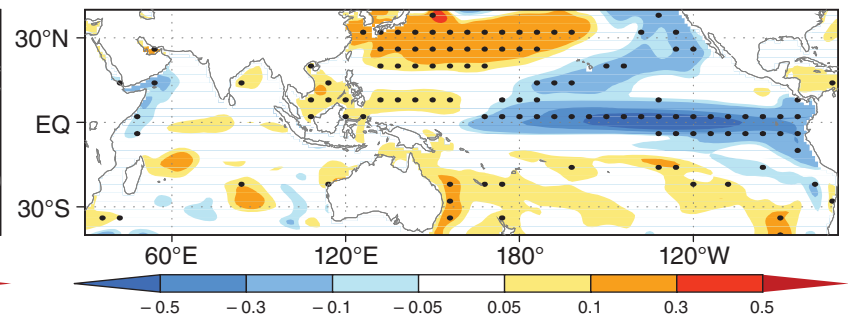

Figure 10. Regressions of preceding spring and summer SST anomalies onto PC2 of summer precipitation anomalies for (a, b) reanalysis and (c, d) BCC_CSM. The dotted areas indicate the 95\% confidence level. [Colour figure can be viewed at wileyonlinelibrary.com].

first leading mode of the summer precipitation to the SST anomalies over tropical Indian ocean is not in good agreement between the reanalysis and the model, which might be one of the reasons that the model reproduced first leading precipitation mode has differences from the reanalysis.

An evolution of PC2 regressed SST anomalies conditions from preceding spring to summer is presented in Figures 10(a) and (b), reflecting that the second mode of summer precipitation over NA is the response to the SST forcing associated with the developing La Nina conditions over tropical East Pacific and the developing cold SST anomalies over the tropical Indian Ocean (Wiedermann et al., 2016). SST regressions in the BCC_CSM in Figures 10(c) and (d) exhibit cold SST circumstances evolved from a weak phase to a strong one in the tropical Pacific, implying that the second mode associated atmospheric responses to the SST forcing in the model are in phase with the developing La Nina condition in the reanalysis. Meanwhile, significant ACCs of SST between reanalysis and BCC_CSM hindcasts dominate the most tropical Pacific region in both spring (Figure 11(a)) and summer (Figure 11(b)), indicating that the BCC_CSM has the ability to reproduce the SST anomalies over the tropical region. The BCC_CSM integration starts from March 1 for spring SST prediction, which is 1 month prior to the summer SST prediction, leading to correlations for spring prediction more significant than summer. Based on the above analysis, we suppose that_BCC_CSM is able to 
(a) Corr. SST MAM

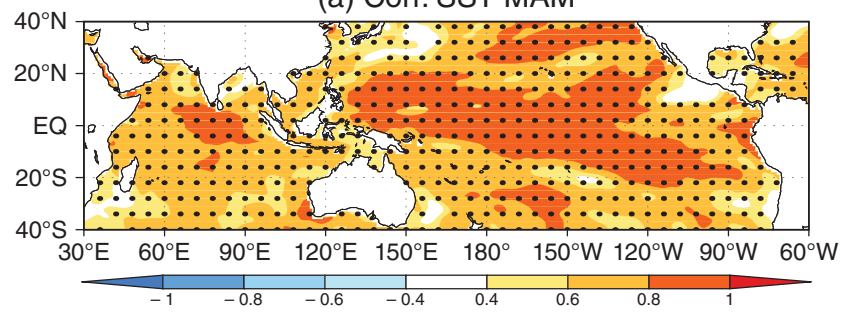

(b) Corr. SST JJA

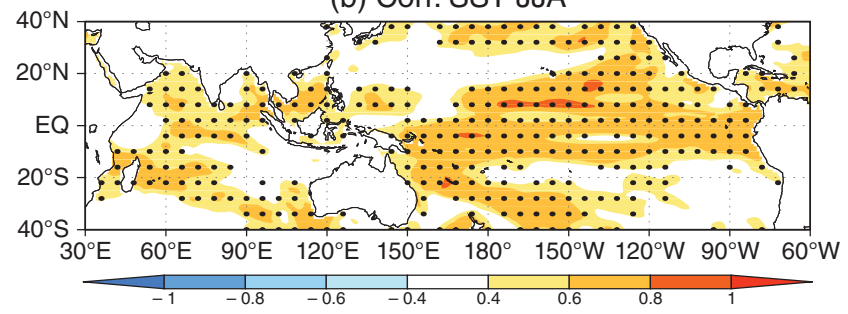

Figure 11. Spatial distribution of correlation coefficients between reanalysis and BCC_CSM for (a) preceding spring and (b) summer. The dotted areas indicate the $95 \%$ confidence level. [Colour figure can be viewed at wileyonlinelibrary.com].

reproduce the SST anomalies over the tropical region and to reproduce part of the general tele-relationship between the leading precipitation modes and ENSO conditions. That is probably the reason the BCC_CSM has the ability to reproduce part of the spatial characteristics of the leading modes of summer precipitation over NA. Nevertheless, it is also noted that SST regressions (Figures 10(c) and (d)) show obvious differences between the BCC_CSM and reanalysis. For example, the SST anomaly tongue from the middle to eastern tropical Pacific is much longer and narrower in the BCC_CSM, SST anomalies over the tropical Indian Ocean are out of phase with the reanalysis (Liu et al., 2015). These differences might be the external factors causing the model's deficiency in capturing the correct remote atmospheric remote responses to the tropical East Pacific SST and Indian Ocean SST forcing, they may result in the model's failure of reproducing the perfect leading modes of the summer precipitation over NA, which might also be the reason for the low summer precipitation prediction accuracy over the NA.

\section{Correcting BCC_CSM's leading modes of summer precipitation over NA}

In the above sections, we analysed the BCC_CSM's ability to predict summer precipitation over NA, revealed model's deficiencies to reproduce the leading modes of summer precipitation, and attributed its possible association with tropical Pacific SST and Indian Ocean SST. The dynamical prediction of the summer precipitation is still an arduous task because of its uncertainty (Wang et al., 2015). Improving the model's ability to reproduce the leading modes of the summer precipitation through normal way, i.e. modifying the model's physical process, parameterization, or initialization process, will require massive efforts and cost lots of time and resources on correcting those problems. Therefore, those normal ways are not very practical in a short-term period (Huang et al., 1993; Li et al., 2001; Li et al., 2008). According to the previous study (Chou, 1986), a practical way of merging dynamical and historical analogue information could be used for improving the model's prediction skill in a very efficient way, on conditions of attributing the model's deficiency in the short-term climate predictions. Therefore, this section will discuss how to dig out the historical analogue information and to correct BCC_CSM's prediction bias in summer precipitation over NA through the dynamic-statistic combined approach.

According to previous studies (Huang et al., 1993; Wang et al., 2015), SST series could be used for digging out the historical analogue prediction errors in the BCC_CSM's hindcasts. Then analogue prediction errors will be combined with current prediction and comes to the purpose of improving the summer precipitation prediction accuracy over NA. Based on this basic idea, the dynamic-statistic combined approach (Gong et al., 2015; Gong et al., 2016a) is proposed in this study for correcting the BCC_CSM's summer precipitation prediction. The main steps are as follows: (1) calculate the average SST over certain region as the SST index, and produce the difference series, DT, of the preceding spring SST index between current year and other year using Equation (1), and then select 5 years with the smallest DT as the current spring SST's analogue external conditions; (2) calculate the average prediction error $\bar{E}$ using the selected 5 year's prediction error, $E_{\text {ana }}$, based on Equation (2); (3) combine the current BCC_CSM's summer precipitation prediction, $P_{0}$, with the average prediction error $\bar{E}$ using Equation (3) for getting the corrected prediction $P$.

$$
D T(i)=a b s[T(i)-T(0)] \quad(i=1,2,3 \ldots, N)
$$

where, $T(i)$ is the SST index, $T(0)$ is the current spring SST, $N$ is the length of the SST index.

$$
\begin{aligned}
& \bar{E}(\mathrm{i})=\frac{1}{5} \sum_{k=1}^{5} E_{\text {ana }}(k) \quad(i=1,2,3, \ldots N) \\
& P(i)=P_{0}(i)+\bar{E}(i) \quad(i=1,2,3 \ldots, N)
\end{aligned}
$$

Since BCC_CSM's low prediction accuracy is associated with the incorrect remote atmospheric responses to the tropical East Pacific SST and Indian Ocean SST forcing, four key SST regions located on the tropical Indian Ocean and the tropical Pacific Ocean are selected as predictors for digging out the historical analogue prediction errors. The annual series of spring SST averaged over the tropical Indian Ocean $\left(50^{\circ}-60^{\circ} \mathrm{E}, 10^{\circ}-5^{\circ} \mathrm{S}, \mathrm{SST} 1\right)$, the tropical Pacific Ocean I $\left(170^{\circ}-180^{\circ} \mathrm{W}, 10^{\circ}-15^{\circ} \mathrm{S}, \mathrm{SST} 2\right)$, the tropical Pacific Ocean II $\left(140^{\circ}-150^{\circ} \mathrm{W}, 0^{\circ}-5^{\circ} \mathrm{N}, \mathrm{SST} 3\right)$, and the tropical Pacific Ocean III $\left(90^{\circ}-100^{\circ} \mathrm{W}, 5^{\circ}-10^{\circ} \mathrm{N}\right.$, SST4) are calculated, respectively. Figure 12 shows the 
(a) TCC SST1 \& ERROR

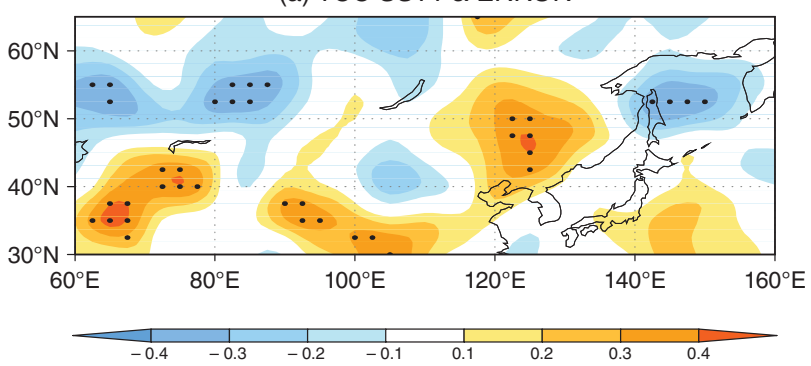

(c) TCC SST3 \& ERROR

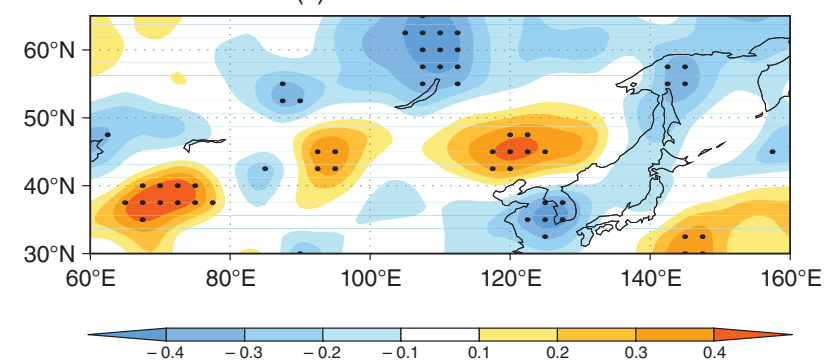

(b) TCC SST2 \& ERROR

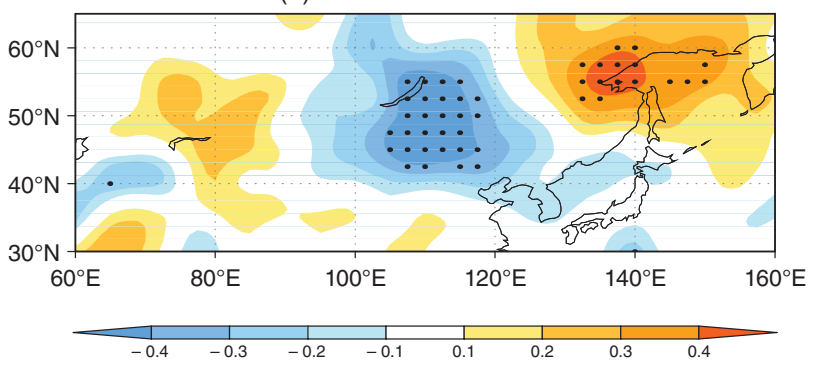

(d) TCC SST4 \& ERROR

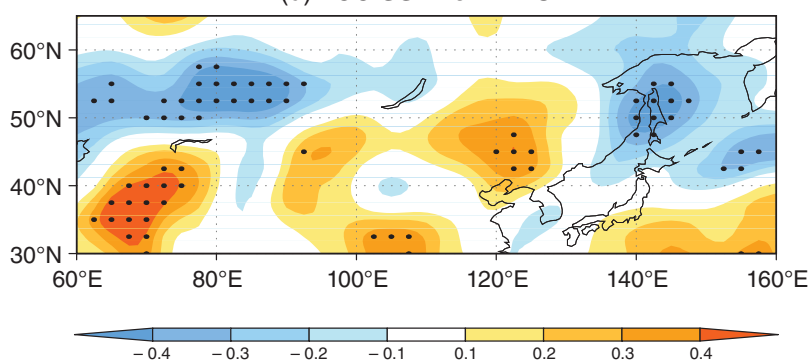

Figure 12. Spatial distribution of anomaly correlation coefficients of BCC_CSM's summer precipitation prediction errors with (a) SST1, (b) SST2, (c) SST3, and (d) SST4 during 1991-2015. [Colour figure can be viewed at wileyonlinelibrary.com].

(a) TCC PREC CMAP \& CORRECTED BCC_CSM SST1

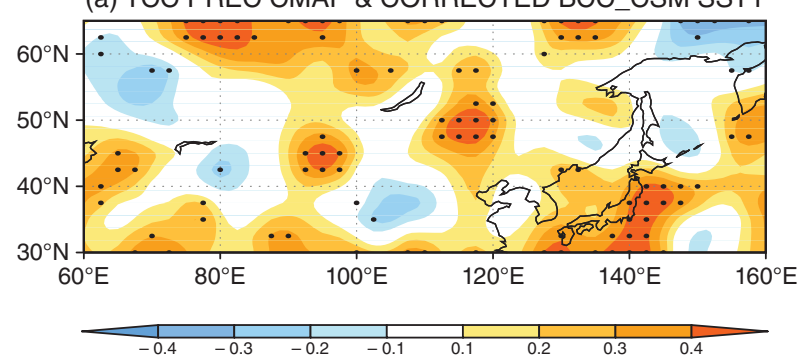

(b) TCC PREC CMAP \& CORRECTED BCC_CSM SST2 - 4

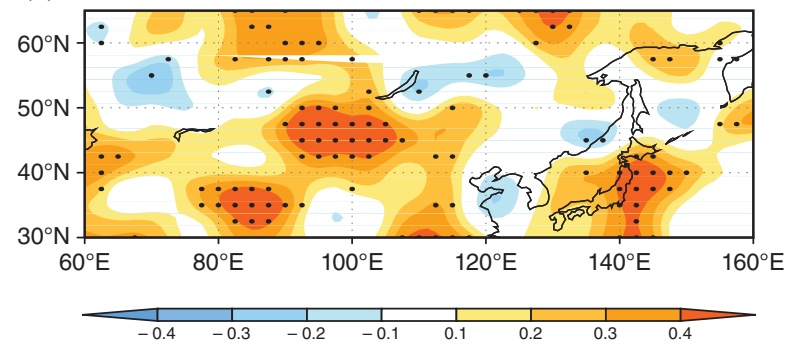

Figure 13. Spatial distribution of temporal anomaly correlation coefficients (TACC) between the corrected summer precipitation prediction and reanalysis during 1991-2015 based on index (a) SST1 and (b)

SST2-4. [Colour figure can be viewed at wileyonlinelibrary.com].

spatial distribution of ACCs of BCC_CSM's summer precipitation prediction errors with the calculated four SST series. Significant correlations for SST1, SST3, and SST4 sparsely distributed from west to east over NA, respectively, while significant correlations for SST2 mainly concentrated on regions southeast of Baikal Lake and Far East Russia. That is to say, BCC_CSM's summer precipitation prediction errors may have close correlation with these four SST series.

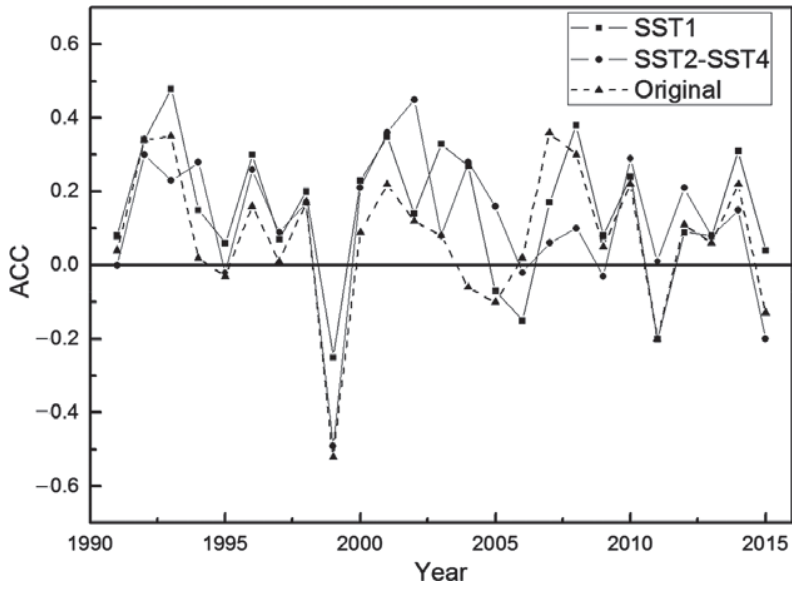

Figure 14. Annual ACCs between summer precipitation prediction and reanalysis.

Based on these four SST series and the proposed correction approach, predictions for summer precipitation over NA are cross validated by verifying the skills of all the hindcasts from 1991 to 2015 . Since we want to merge the historical analogue information associated with tropical Pacific SSTs, corrected predictions based on SST2, SST3, and SST4 are combined using Equation (4).

$$
\begin{aligned}
P(i)= & a P_{0}(i)+\left[b P_{\mathrm{SST} 2}(i)+c P_{\mathrm{SST} 3}(i)+d P_{\mathrm{SST} 4}(i)\right] / 3 \\
& +\varepsilon \quad(i=1,2,3 \ldots, N)
\end{aligned}
$$

where, regression parameters $a=1, b=1, c=0.5$, $d=-0.5$, while $\varepsilon$ is the residual item.

Comparing with Figure 1, temporal anomaly correlation coefficients (TACCs) of the corrected summer 
(a) PREC EOF1 CSM Revised SST1

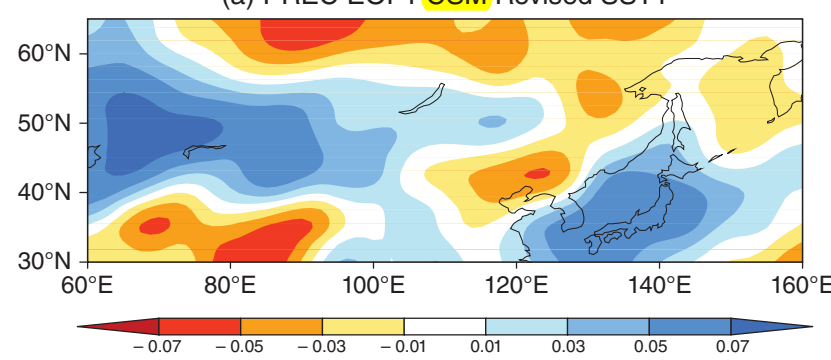

(c) PREC EOF1 CSM Revised SST2 - 4

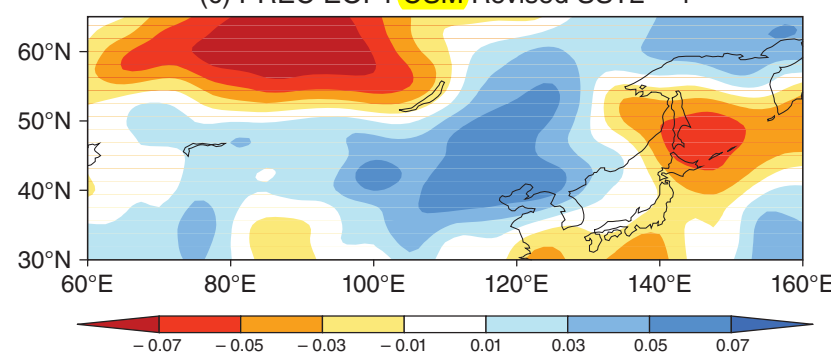

(b) PREC EOF2 Revised SST1

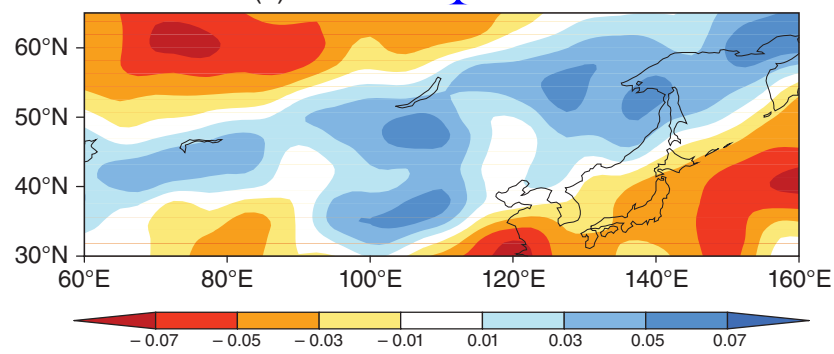

(d) PREC EOF2 Revised SST2 - 4

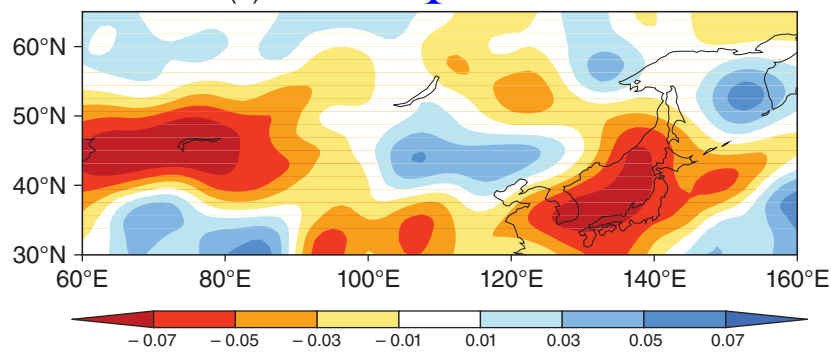

Figure 15. Same as Figure 2 but for the corrected two leading modes of summer precipitation prediction based on (a, b) SST1, (c, d) SST2- SST4. [Colour figure can be viewed at wileyonlinelibrary.com].

precipitation prediction based on SST1 (Figure 13(a)) show obvious improvement over central north part of the land region. SST2- to SST4-based corrections present significant correlation over central and southeastern NA (Figure 13(b)). Anntal evolution of ACCs between summer precipitation prediction and reanalysis-(14), in which the triangle dash curve denotes the ACCs of BCC_CSM original prediction, the square and dot curves denote the ACCs of SST1 and SST2- to SST4-based corrections, respectively. It is also indicated obvious improvement of prediction accuracy for SST1 and SST2- to SST4-based corrections with 20 of 25 years having improved ACCs for both corrections.

Figure 15 shows the leading modes of corrected summer precipitation prediction over NA. For the SST1-based correction, variance percentage is $16.2 \%$ for EOF1 and $14.1 \%$ for EOF2. The corrected EOF1 presents the similar spatial anomalies pattern (Figure 15(a)) as reanalysis observation (Figure 2(a)) over the most part of NA. Compared to the leading modes of BCC_CSM's original prediction, the ACC of EOF1 is improved from 0.18 to 0.51 and the TACC of PC1 is improved from 0.40 to 0.57 , indicating obvious improvements in the first dominate mode. The corrected EOF2 (Figure 15(b)) also shows improved anomaly distribution over some parts of NA with the ACC of EOF2 being improved from 0.36 to 0.61 , and the TACC of $\mathrm{PC} 2$ being improved from 0.06 to 0.18 . Moreover, for the SST2- to SST4-based correction, variance percentage is $14.2 \%$ for EOF1 and $13.1 \%$ for EOF2. The corrected EOF1 (Figure 15(c)) and EOF2 (Figure 15(d)) present the quite similar spatial anomalies pattern as reanalysis observations (Figure 2(a)), with ACC of EOF modes between corrected prediction and reanalysis being 0.65 and 0.19 , respectively. The
TACCs of PC1 and PC2 are improved to 0.17 and 0.38 , respectively. Therefore, the dynamic-statistic combined correction approach has the potential possibility to be used for improving the prediction accuracy and leading modes of the summer precipitation over NA by merging the tropical SST-associated historical analogue information.

\section{Conclusions and discussion}

Previous studies have identified that the summer precipitation over NA is influenced by the zonal and meridional wave activities, which form the leading modes representing the main predictable part of NA summer precipitation variability. This study presents the BCC_CSM's prediction accuracy of summer precipitation over NA and analyses its possible connection with model's ability to predict the first two leading modes of NA summer precipitation, attributes possible reasons to the atmospheric internal process and tele-atmosphere responses to the tropical SST forcing. Then, based on the dynamic-statistic combination concept, a new approach is proposed to improve BCC_CSM's accuracy in predicting NA summer precipitation. Main conclusions are as follows.

1) BCC_CSM exhibits limited prediction skill over part of Southeast NA and Northeast NA. Although model can capture part of the spatial anomaly characteristics of the first two leading modes of NA summer precipitation, it has the deficiency in reproducing the EOF1's spatial pattern and EOF2's interannual variability, especially it lacks in the ability to reproduce the anomaly precipitation pattern in central NA.

2) The correlations among the summer precipitation, geopotential height anomalies, and vertical velocity in 
(a) Reg. ENSO\&Rain CMAP

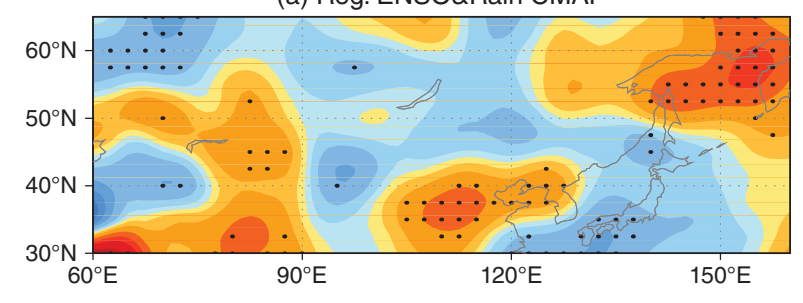

(b) Reg. ENSO\&Rain CSM

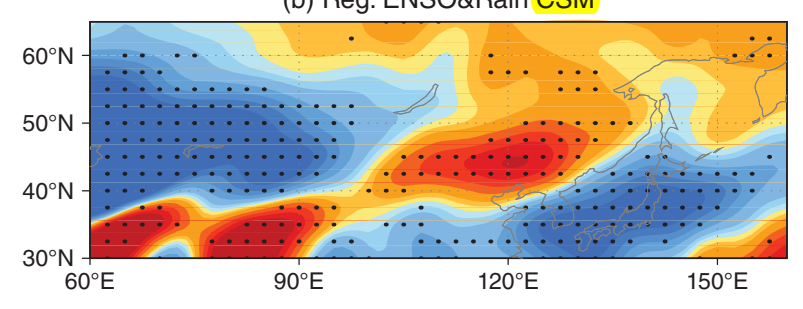

(c) Reg. ENSO\&Rain CSM REVISED

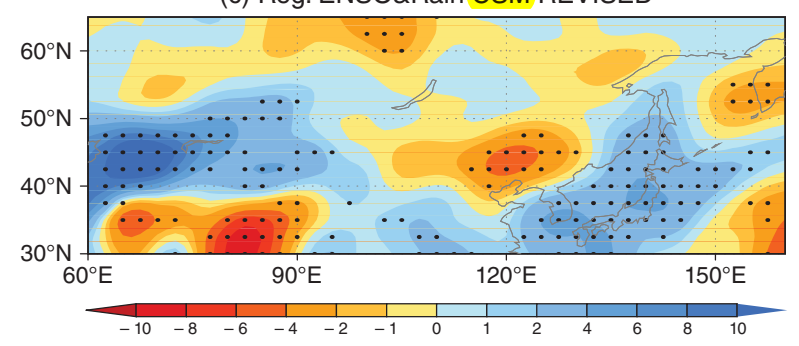

Figure 16. Regression of summer precipitation anomaly percentage (unit: \%) onto the SST series averaged over the tropical East Pacific $\left(120^{\circ}-150^{\circ} \mathrm{W},-5^{\circ} \mathrm{S}-5^{\circ} \mathrm{N}\right)$ for (a) reanalysis, (b) BCC_CSM prediction, and (c) corrected prediction. Dotted areas indicate the $95 \%$ significance level. [Colour figure can be viewed at wileyonlinelibrary.com].

the western and eastern NA are well captured in the BCC_CSM hindcasts during 1991-2015. Nevertheless, the model fails to reproduce the correct relationships among basic atmospheric elements over central NA, causing BCC_CSM's failure to predict the wave pattern indicated in the geopotential height anomalies. Due to these shortcomings, the model reproduces inconsistent zonal atmosphere anomalous pattern over NA, causing the EOF1's spatial pattern and EOF2's interannual variability of the NA summer precipitation not to be properly predicted by the BCC_CSM, resulting in the low prediction accuracy for the summer precipitation over the NA.

3) The EOF1 and EOF2 of the NA summer precipitation are, respectively, associated with the developing conditions of the El Nino and La Nina events over the tropical East Pacific, which are partially captured by the BCC_CSM. This seems to be the reason that model reproduces part of the spatial characteristics of the leading modes of the NA summer precipitation. However, BCC_CSM predicted cold SST over tropical East Pacific corresponding to the EOF modes of summer precipitation has a longer but narrower tongue than the reanalysis, and reproduced SST anomalies over the tropical Indian Ocean are out of phase with the reanalysis, which may cause the bias ef, remote atmospheric response to the tropical East
Pacific SST and Indian Ocean SST forcing and lead to the prediction errors in summer precipitation over NA.

4) Based on the attribution analysis relevant to the atmospheric process and SST forcing, the dynamic-statistic combined correction approach is proposed for improving the prediction accuracy of the NA summer precipitation and correcting the BCC_CSM's leading modes and PCs of summer precipitation over the NA. A cross-validation experiment shows that the TACCs of the NA summer precipitation prediction have been apparently improved over many parts of the NA by using the tropical SST to dig out historical analogue prediction errors. Comparing with the leading modes of BCC_CSM's original prediction, ACCs of corrected EOF1/EOF2 based on tropical Indian Ocean SST are improved from $0.18 / 0.36$ to $0.51 / 0.62$, and it is 0.65/0.19 for the tropical East Pacific SST-based correction. That is to say, the BCC_CSM's prediction skill for the summer precipitation prediction over NA and its ability to capture the dominant modes can be obviously improved with the condition of getting proper historical analogue information.

The dynamic-statistic combined correction approach is proposed for improving the prediction accuracy of the NA summer precipitation, which may overcome shortcomings of a statistic alone or a dynamic alone method. Chou (1986) and Huang et al. (1993) argued that it is possible to use the analogue information contained in the historical observation to remedy the defects of the numerical model and so to improve numerical climate prediction. The tropical East SSTs have distinct influence on summer precipitation over East Asia and the relationship between leading modes of NA summer precipitation and the tropical SSTs produced by BCC_CSM is not consistent with the reanalysis, implying that the model prediction errors may have close relationship with the tropical SSTs, therefore, historical analogue prediction errors selected based on the tropical SST can be used to correct the model output, which may have great values of improving precipitation forecast skill.

Figure 16 shows regression of summer precipitation onto the SST series averaged over the tropical East Pacific, reflecting the ENSO information contained in the summer precipitation field of the reanalysis observation, the BCC_CSM prediction and the corrected prediction, respectively. Compare to the reanalysis (Figure 16(a)) the significantly regressed area in the BCC_CSM prediction (Figure 16(b)) is much larger, implying the ENSO information contained in the summer precipitation prediction is over estimated by the BCC_CSM, while the significant area in the corrected prediction (Figure 16(c)) is obviously reduced and is more consistent with the reanalysis. Accordingly, the information relevant to the ENSO contained in the BCC_CSM's summer precipitation prediction in NA can be improved through the statistic-dynamic combined correction, it is also the reason why the tropical East SST could be used for improving the BCC_CSM prediction accuracy of summer precipitation. 
The accuracy with which reanalysis reproduce observed climate varies widely, with radioactive quantities having the biases (Reichler and Kim, 2008), therefore the original and corrected ACCs of the NA summer precipitation prediction may have uncertainties. The ACCs of corrected EOF1/EOF2 of NA summer precipitation based on the tropical Indian Ocean SST are improved to $0.51 / 0.62$, which is the cross-validation result rather than the real-time prediction, implying this improvement may also has its uncertainty in the practical use. Furthermore, although variance percentage of EOF1 and EOF2 in this study is only about $30 \%$ in total, however, they are respectively the first and second mode of the EOF analysis, which have more variance percentage compared to others, therefore we take EOF1 and EOF2 as the leading modes in our study.

\section{Acknowledgements}

The authors wish to thank three anonymous reviewers' meaningful comments that led to a much-improved manuscript. This work is supported by the National Natural Science Foundation of China (Grant Nos. 41575082 and 41475064), the Special Scientific Research Project for Public Interest (Grant No. GYHY201306021).

\section{References}

Aizen EM, Aizen VB, Melack JM, Nakamura T, Ohta T. 2001. Precipitation and atmospheric circulation patterns at mid-latitudes of Asia Int. J. Climatol. 21(5): 535-556.

Chen G, Huang R. 2012. Excitation mechanisms of the teleconnection patterns affecting the July precipitation in Northwest China. J. Clim. 25(22): 7834-7851.

Chen XL, Zhou TJ. 2014. Relative role of tropical SST forcing in the 1990s periodicity change of the Pacific-Japan pattern interannual variability. J. Geophys. Res. Atmos. 119: 13043-13066.

Chen G, Huang R, Zhou L. 2013. Baroclinic instability of the silk road pattern induced by thermal damping. J. Atmos. Sci. 70(9): 2875-2893.

Chou JF. 1986. Why to combine dynamical and statistical methods together and how to combine (in Chinese). Plateau Meteorol. 5: 367-372.

Ding QH, Wang B. 2005. Circumglobal teleconnection in the northern hemisphere summer. J. Clim. 18: 3483-3505.

Ding YH, Wang ZY, Sun Y. 2008. Inter-decadal variation of the summer precipitation in East China and its association with decreasing Asian summer monsoon. Part I: observed evidences. Int. J. Climatol. 28(9): 1139-1161.

Dogar MM, Kucharski F, Azharuddin S. 2017. Study of the global and regional climatic impacts of ENSO magnitude using SPEEDY AGCM. J Earth Syst. Sci. 126(2): 30.

Fan K, Liu Y, Chen H. 2012. Improving the prediction of the east Asian summer monsoon: new approaches. Weather Forecast. 27(4): 1017-1030.

Feng G, Zhao J, Zhi R, Gong Z. 2013. Recent progress on the objective and quantifiable forecast of summer precipitation based on dynamical statistical method. J. Appl. Meteorol. Sci 24: 656-665.

Gao ZT, ZZ H, Zhu JH, Yang S, Zhang RH, Xiao Z, Jha B. 2014. Variability of summer rainfall in Northeast China and its connection with spring rainfall variability in the Huang-Huai region and Indian Ocean SST. J. Clim. 27(18): 7086-7101.

Gong ZQ, Zhao JH, Feng GL, Chou JF. 2015. Dynamic-statistics combined forecast scheme based on the abrupt decadal change component of summer precipitation in East Asia. Sci. China Ser. D: Earth Sci. 58(3): 404-419.

Gong ZQ, Hutin C, Feng GL. 2016a. Methods for improving the prediction skill of summer precipitation over East Asia-West Pacific. Weather Forecasting 31(4): 1381-1392.
Gong ZQ, Li SF, Hu P, Shen BZ, Feng GL. 2016b. Dynamic-analogue correction of the decadal change of east Asian summer precipitation in the late 1990s. J. Meteorol. Res. 30(3): 341-355.

Gong ZQ, Dogar MMA, Qiao SB, Hu P, Feng GL. 2017. Limitations of BCC_CSM's ability to predict summer precipitation over East Asia and the northwestern Pacific. Atmos. Res. 193: 184-191.

He WP, Feng GL, Wu Q, Wan SQ, Chou JF. 2008. A new method for abrupt change detection in dynamic structures. Nonlinear Processes Geophys. 15(4): 601-606.

He WP, Liu QQ, Gu B, Zhao SS. 2016. A novel method for detecting abrupt dynamic change based on the changing Hurst exponent of spatial images. Clim. Dyn. 47(7-8): 2561-2571.

Huang RH. 1987. Influence of the Heat Source Anomaly over the Tropical Western Pacific on the Subtropical High over East Asia, In International Conference on the General Circulation of East Asia, Chengdu, 40-51.

Huang JP, Yi YH, Wang SW, Chou JF. 1993. An analogue-dynamical long-range numerical weather prediction system incorporating historical evolution. Q. J. R. Meteorol. Soc. 119(511): 547-565.

Huang RH, Liu Y, Feng T. 2012. Interdecadal change of summer precipitation over eastern China around the late-1990s and associated circulation anomalies, internal dynamical causes. Chin. Sci. Bull. 58(12): 1339-1349.

Huang W, Chen F, Feng S, Chen J, Zhang X. 2013. Interannual precipitation variations in the mid-latitude Asia and their association with large-scale atmospheric circulation. Chin. Sci. Bull. 58(32): 3962-3968

Iwao K, Takahashi M. 2008. A precipitation seesaw mode between northeast Asia and Siberia in summer caused by Rossby waves over the Eurasian continent. J. Clim. 21(11): 2401-2419.

Kosaka Y, Nakamura H, Watanabe M, Kimoto M. 2009. Analysis on the dynamics of a wave-like teleconnection pattern along the summertime Asian jet based on a reanalysis dataset and climate model simulations. J. Meteorol. Soc. Jpn 87(3): 561-580.

Kwon M, Jhun JG, Ha KJ. 2007. Decadal change in east Asian summer monsoon circulation in the mid-1990s. Geophys. Res. Lett. 34: L21706.

Lang X, Wang H. 2010. Improving extraseasonal summer rainfall prediction by merging information from GCMs and observations. Weather Forecast. 25(4): 1263-1274.

Li JP, Zeng QC, Chou JF. 2001. Computational uncertainty principle in nonlinear ordinary differential equations. Sci. China Ser. E: Technol. Sci. 44(1): 55-74.

Li JP, Chou JF, Wang SH. 2008. Some mathematical and numerical issues in geophysical fluid dynamics and climate dynamics. Commun. Comput. Phys. 3: 759-793.

Liu Y, Fan K. 2013. A new statistical downscaling model for autumn precipitation in China. Int. J. Climatol. 33(6): 1321-1336.

Liu X, Wu T, Yang S, Jie W, Nie S, Li Q, Cheng Y, Liang X. 2015. Performance of the seasonal forecasting of the Asian summer monsoon by BCC_CSM1.1(m). Adv. Atmos. Sci. 32(8): 1156-1172.

Lu RY. 2004. Associations among the components of the east Asian summer monsoon system in the meridional direction. J. Meteorol. Soc. Jpn 82(1): 155-165.

Lu RY. 2005. Interannual variation of North China rainfall in rainy season and SSTs in the equatorial eastern Pacific. Chin. Sci. Bull. 50(18): 2069-2073.

Lu RY, JH O, Kim BJ. 2002. A teleconnection pattern in upper-level meridional wind over the north African and Eurasian continent in summer. Tellus A 54(1): 44-55.

Masao K, Wesley E, Jack W, Shi-Keng Y, Hnilo JJ, Fiorino M, Potter GL. 2002. Ncep-doe amip-ii reanalysis (r-2). Bull. Am. Meteorol. Soc. 83(11): $1631-1643$.

Nitta T. 1987. Convective activities in the tropical western Pacific and their impact on the northern hemisphere summer circulation. $J$. Meteorol. Soc. Jpn 65(3): 373-390.

Reichler T, Kim J. 2008. Uncertainties in the climate mean state of global obervations, reanalyses, and the GFDL climate model. J. Geophys. Res. Atmos. 113(D5): 79-88.

Smith TM, Reynolds RW, Peterson TC, Lawrimore J. 2008. Improvements to NOAA's historical merged land-ocean surface temperature analysis (1880-2006). J. Clim. 21(10): 2283-2296.

Wang B, Yang J, Zhou TJ, Wang B. 2008. Interdecadal changes in the major modes of Asian Australian monsoon variability: strengthening relationship with ENSO since the late 1970s. J. Clim. 21(8): $1771-1789$.

Wang QJ, Schepen A, Robertson DE. 2012. Merging seasonal rainfall forecasts from multiple statistical models through Bayesian model averaging. J. Clim. 25(16): 5524-5537. 
Wang HJ, Fan K, Sun JQ, Li SL, Lin ZH, Zhou GQ, Chen LJ, Lang XM, $\mathrm{Li} \mathrm{F}$, Zhu YL. 2015. A review of seasonal climate prediction research in China. Adv. Atmos. Sci. 32(2): 149-168.

Wiedermann M, Radebach A, Donges JF, Kurths J, Donner RV. 2016. A climate network-based index to discriminate different types of el Niño and la Niña. Geophys. Res. Lett. 43(13): 7176-7185.

Wu TW, Song LC, Liu XW. 2013. Progress in developing the short-range operational climate prediction system of China National Climate Center. J. Appl. Meteorol. Sci 24(5): 533-543.

Xie PP, Arkin PA. 1997. Global precipitation: a 17-year monthly analysis based on gauge observations, satellite estimates, and numerical model outputs. Bull. Am. Meteorol. Soc. 78(11): 2539-2558.

Xiong KG, Feng GL, Huang JP, Huang JF. 2011. Analogue-dynamical prediction of monsoon precipitation in Northeast China based on dynamic and optimal configuration of multiple predictors. J. Meteorol. Sci. 25(3): 316-326.

Yang JL, Liu QY, Xie SP, Liu ZY, Wu LX. 2007. Impact of the Indian Ocean SST basin mode on the Asian summer monsoon. Geophys. Res. Lett. 34: L02708.

Zhou LT, Huang RH. 2010. Interdecadal variability of summer rainfall in Northwest China and its possible causes. Int. J. Climatol. 30(4): $549-557$.

Zhou TJ, Wu B, Wang B. 2009. How well do atmospheric general circulation models capture the leading modes of the interannual variability of the Asian-Australian monsoon? J. Clim. 22(5): 1159-1173.

Zhou TJ, Song FF, Lin RP, Chen XL, Chen XY. 2013. The 2012 North China floods: explaining an extreme rainfall event in the context of a longer term drying tendency. Bull. Am. Meteorol. Soc. 94(9): S49. 